\title{
Practice and Reflection on Cultivating Students' Innovative Ability in Mathematical Modeling Teaching
}

\author{
Yuanfu Mao \\ (Nanchang Institute of Science \& Technology, Nanchang 330108)
}

\begin{abstract}
Keywords: Mathematical modeling; Curriculum teaching; Innovation ability
\end{abstract}
\begin{abstract}
Mathematical modeling is a course that focuses on theory and practice. It helps to cultivate students' imagination and insight. It helps to cultivate students' intuitive thinking and divergent thinking. It helps to develop students' practical ability and self-evaluation. In the methods of cultivating innovation ability, the several following points should be emphasized: focus on accumulation, optimize the knowledge structure; guide thinking, pay attention to cognitive process; design teaching, to promote intuitive thinking; various changes to a question, strengthen divergent thinking; cultivate innovative character. Strengthening the teaching of mathematical modeling is put forward in this teaching situation. This is not only in line with the needs of the development of mathematics itself, but also the needs of social development. Because our math teaching not only enables students to acquire new knowledge but also improves students' thinking ability, cultivate students to consciously use mathematical knowledge to consider and deal with daily life, production problems encountered in order to form a good quality of thinking to create a new generation of people with new knowledge, new methods and creative thinking ability.
\end{abstract}

\section{Introduction}

With the deepening of teaching reform, China is currently carrying out quality education as the core of educational thinking, in order to fully implement the quality of education, colleges and universities only change the traditional concept of education and education, focus on strengthening quality education, and pay attention to students' personality development in order to continuously cultivate a solid foundation, wide knowledge, high-quality innovative and applied talents in order to adapt to the future development of society. Ten years of college mathematics teaching reform practice shows that to carry out mathematical modeling teaching activities is a mathematical teaching reform a useful attempt and practice. It is not only an effective way to carry out quality education for college students, but also an important way to cultivate high-quality talents with innovative ideas and solidarity. Mathematical innovation is an important aspect of innovative education. Mathematical innovation is not only the innovation of mathematical theory, but also the innovation of mathematics application. And mathematical modeling teaching is the best embodiment of the application of innovation. Traditional mathematics teaching system and content are focused on theory, which makes the original boring mathematics so many people discouraged. Mathematical modeling plays a role that cannot be replaced by other courses. Mathematical modeling courses and activities are the best training for students to use math to solve practical problems. Especially the rapid development of computer technology and mathematical software, mathematical modeling provides a very good platform. Mathematical modeling teaching activities so that students out of the textbooks, out of the traditional exercises, so that they enter the production and life of reality, into a more open world, so that students understand the origin of mathematics, the application of mathematics, experience to a vibrant Teaching, in such teaching practice activities to strengthen students' quality education and training innovation ability. It is clearly a unique and important way.

\section{Mathematical Modeling and Mathematical Modeling Consciousness}

The famous mathematician Whitehead once said: "Mathematics is the study of the model." The so-called mathematical model refers to a particular research object for the real world, for a specific 
purpose, to do some necessary simplified assumptions, the use of appropriate mathematical tools, and through mathematical language expressed a mathematical structure, mathematics In the various basic concepts, are their respective real prototype as a background and abstract mathematical concepts. The ability of students to obtain this ability is not a matter of time, the need for mathematical modeling awareness throughout the teaching of the end, that is, to continue to guide students to use mathematical thinking to observe, analyze and express a variety of things, Mathematical information, from the complex and specific problems in the abstract we are familiar with the mathematical model, and then to use mathematical models to solve practical problems, so that mathematical modeling awareness as a way to think about students and habits.

\section{Basic Ways of Constructing Mathematical Modeling Consciousness}

In order to cultivate students' sense of modeling, math teachers should first need to improve their sense of modeling. This not only means that we in the teaching content and requirements on the changes, but also means that education and teaching ideas of the update. In addition to the need to understand the history of mathematics science development and development trends, but also need to continue to learn some new mathematical modeling theory, and efforts to study how to apply middle school mathematics knowledge in real life.

Mathematical modelling teaching should also be combined with the existing teaching materials. In this way, through pre-chapter teaching, students can understand that math is to learn, study and apply mathematical models, which can also cultivate students' awareness of pursuing new methods and participating in practice. Therefore, we should pay attention to the teaching of pre-chapter problems and supplement some examples according to demands of constructing and developing the market economy and problems found in students' practical activities, enhance teaching in this aspect so as to make students pay attention to math in daily life and study and cultivate their mathematical modeling consciousness.

Pay attention to the relationship with other related disciplines. Because mathematics is a tool for students to learn from other natural sciences and social sciences, and other disciplines are in close contact with mathematics. Therefore, we should pay attention to the teaching and other disciplines echo, which not only can help students to deepen the understanding of other disciplines, but also cultivate students a sense of modeling awareness cannot be ignored, and they will learn from other disciplines of knowledge and future use Mathematical modeling knowledge to explore the various marginal disciplines have far-reaching impact.

\section{Mathematical Modeling Classroom Teaching Principles}

Subjective principle. In the teaching of mathematical modeling to effectively implement the subject of teaching, teachers must first clear the teaching process who is the subject, who is the object of this fundamental problem, but also clear the fundamental purpose of teaching. According to the principle of dialectical materialism, "teaching" is two aspects of a thing, both teachers "teach", and students "learning", "teaching" and "learning" is a contradictory unity, in the contradiction, the students' "learning" is the main aspect of the main contradiction and contradiction. Teachers '"teaching" only acts on the students' "learning", only through the students to take the initiative to learn, to play a role, the teacher's "teaching" only through the student's internalization in order to achieve its "teaching" value. Teachers, teaching materials and teaching methods for students to learn are the media, the object, and students themselves is the main body of learning, students learn their own master, is to determine their own destiny "savior." This is conducive to students' subjective initiative to play.

Principle of activity. Mathematical modeling teaching process is the dynamic process of interaction between teachers and students. It is the process of teacher-student interaction, positive interaction and common development. The realization of this process is based on the activity as the carrier, and there is no real teaching. Traditional teaching only teachers "teaching", students only listen to the obligations, there is no "move" the opportunity and power, depress the students to learn 
the autonomy and enthusiasm, but also inhibited the students' creativity. To improve the efficiency and efficiency of classroom teaching, we must strive to make the classroom "activities" up, no students "move" there is no classroom "live", there is no student thinking "live", there is no student creative life. Classroom activities in a variety of forms, teachers should play a real leading role, and urged the formation of interaction between teachers and students, and students' interactive activities, to encourage students to participate in bold participation. Provide conditions and opportunities for students to observe their own, so that students think, so that students express their own, so that students do their own hands, so that students themselves. It is best to encourage students to ask questions to the teacher, the competition between groups competing. You can let the students when the small Mr., their own to speak, demo students invited students to do it, the teacher when the guide, the students do while speaking, and find some students to do, as far as possible to demonstrate the experiment to a group experiment, to expand student participation scope and degree.

The principle of motivation. From a psychological point of view, everyone has the will to make progress, everyone wants to get recognition and respect from others. Encouragement can make people continue to make progress and make people move from failure to success. In our traditional preaching education, teachers criticize students more than praise, doubt more than trust, more than tolerance, to suppress more than encouragement, restraint more than freedom, which has depressed the student's personality, hurt the student's self-esteem, restricting the development of students, so that most students are often expressed as obedient and "low profile", and not "able to being outstanding", and in the long run, they lose the ability and quality to be "outstanding". Therefore, it is an undeniable fact that students' innovation spirit and practical ability are not strong.

\section{Conclusion}

Constructing students' awareness of mathematical modeling in math teaching and cultivating students' innovative thinking in quality teaching are complementary and inseparable. In order to really cultivate students' innovation ability, it is far from enough to just impart knowledge, and the more important thing is to insist on that students are the main body in teaching, and we cannot carry out some unrealistic modeling teaching that are separated from students. All our teaching activities must emphasize students' subjective initiative, start from cultivating students' innovative thinking, guiding students' independent activities, and making students consciously construct mathematical modeling awareness in the learning process so that students can make lasting progress in analyzing and solving problems. And only in this way, students' innovation ability can be truly improved and students can learn useful math knowledge. We believe that while carrying out "target teaching", to vigorously penetrate "modeling teaching" will provide a new way for the reform of secondary school mathematics classroom teaching and provide a new platform for cultivating more "innovative" talents.

\section{Acknowledgements}

Project Funding: Science and technology research project of Jiangxi Provincial Department of Education (No.GJJ151244)

\section{References}

[1] Howard W R. The Nature of Mathematical Modeling[J]. Kybernetes, 2006, 35(3/4):597 - 597.

[2] Vigneron F R. Comment on "Mathematical Modeling of Spinning Elastic Bodies for Modal Analysis"[J]. Aiaa Journal, 2015, 13(1):126-127.

[3] Silchenko A N, Tass P A. Mathematical modeling of chemotaxis and glial scarring around implanted electrodes[J]. New Journal of Physics, 2015, 17(2).

[4] Chretien J P, Riley S, George D B. Mathematical modeling of the West Africa Ebola epidemic[J]. Elife Sciences, 2015, 4. 
[5] Price P E, Cairncross R A. Optimization of single - zone drying of polymer solution coatings using mathematical modeling[J]. Journal of Applied Polymer Science, 2015, 78(1):149-165.

[6] Olanipekun B F, Tunde - Akintunde T Y, Oyelade O J, et al. Mathematical Modeling of Thin Layer Pineapple Drying[J]. Journal of Food Processing \& Preservation, 2016, 39(6):1431-1441.

[7] Ike I S, Sigalas I, Iyuke S, et al. An overview of mathematical modeling of electrochemical supercapacitors/ultracapacitors[J]. Journal of Power Sources, 2015, 273:264-277.

[8] Ping, Q., et al. "Integrated experimental investigation and mathematical modeling of brackish water desalination and wastewater treatment in microbial desalination cells. "Water Research 77(2015):13-23.

[9] Ni B J, Yuan Z. Recent advances in mathematical modeling of nitrous oxides emissions from wastewater treatment processes[J]. Water Research, 2015, 87:336-346.

[10] Srivastav M K, Nath A. Study on Mathematical Modeling of Social Networks[J]. 2015, volume 5,:611-618.

[11] Sameen S, Barbuti R, Milazzo P, et al. Mathematical modeling of drug resistance due to KRAS mutation in colorectal cancer[J]. Journal of Theoretical Biology, 2016, 389:263-273.

[12] Serpilli M. Mathematical Modeling of Weak and Strong Piezoelectric Interfaces[J]. Journal of Elasticity, 2015, 121(2):1-20. 